\title{
A Systematic Review of Literatures on Factors Associated with Educational and Academic Performance in Attention Deficit Hyperactivity Disorder
}

\author{
Annemarie van der Kolk1,3*, Michel van Agthoven², Jan K. Buitelaar3, \\ Leona Hakkaart-van Roijen ${ }^{4}$ \\ ${ }^{1}$ Janssen-Cilag B.V., Tilburg, The Netherlands \\ ${ }^{2}$ Gilead Sciences Netherlands B.V., Amsterdam, The Netherlands \\ ${ }^{3}$ Radboud UMC, Donders Institute for Brain, Cognition and Behavior, Nijmegen, The Netherlands \\ ${ }^{4}$ Institute for Medical Technology Assessment (iMTA), Rotterdam, The Netherlands \\ Email: ${ }^{*}$ avdkolk@its.jnj.com
}

Received 16 January 2015; accepted 4 February 2015; published 10 February 2015

Copyright (C) 2015 by authors and Scientific Research Publishing Inc.

This work is licensed under the Creative Commons Attribution International License (CC BY). http://creativecommons.org/licenses/by/4.0/

c) (i) Open Access

\begin{abstract}
Attention Deficit Hyperactivity Disorder (ADHD) has been shown to impair major life activities including educational functioning. However, there is no consensus on the specific cause for the impact on this worse educational outcome. This systematic review aims to identify factors that have been associated with educational and academic underperformance of children and adolescents with ADHD. A literature search was conducted using PubMed and the PRISMA guidelines (Preferred Reporting Items for Systematic Reviews and Meta-Analyses). The study focused on articles presenting results of data-based analyses related to ADHD and keywords related to education. The search resulted in 376 records that were screened by title. Of these, 185 articles were screened by abstract and 35 met the eligibility criteria for inclusion in the review. These 35 articles were related to seven domains: educational training, educational environment, pharmacological treatment, ADHD symptoms, associations of ADHD with academic outcomes, self-concept, and specific skills. The main source of educational challenges seems to be related to the inattentive symptoms (or subtype) of ADHD. This outcome is different than expected, since hyperactive symptoms are pronounced more prominently and often refer children to clinical practice. Inattentive symptoms amongst others refer to difficulties in organization skills and can lead to decreased self-efficacy and development of depressive symptoms. This decreased self-efficacy and the depressive symptoms were also found to be related to influence the relation between ADHD and academic perfor-
\end{abstract}

${ }^{*}$ Corresponding author.

How to cite this paper: van der Kolk, A., van Agthoven, M., Buitelaar, J. K., \& Hakkaart-van Roijen, L. (2015). A Systematic Review of Literatures on Factors Associated with Educational and Academic Performance in Attention Deficit Hyperactivity Disorder. Creative Education, 6, 164-180. http://dx.doi.org/10.4236/ce.2015.62015 
mance. Educational outcomes were shown to be improved using small group work, learning via a computer-based service and as a result of coaching and pharmacological treatment. To help children and adults achieve educational goals that now are out of reach, more attention should be spent to the inattentive symptoms of ADHD and possibilities to overcome experienced problems.

\section{Keywords}

\section{ADHD, Education, Academic Performance, PRISMA}

\section{Introduction}

Attention Deficit Hyperactivity Disorder (ADHD) is the most common neuropsychiatric disorder in children and adolescents (Polanczyk, de Lima, Horta, Biederman, \& Rohde, 2007). The prevalence rate is similar across countries in Europe and throughout the world and is estimated at 5.3\% (Polanczyk et al., 2007). Core symptoms of ADHD comprise inappropriate levels of inattention, hyperactivity and impulsivity (Goodman \& Livingston, 2013). Multiple follow-up studies have been published that show ADHD persists into adolescence and adulthood in around two-thirds of the population (Faraone, Biederman, \& Mick, 2006; Lara et al., 2009). Adult ADHD is estimated to have a worldwide-pooled prevalence of 4.4\% (Polanczyk et al., 2007). It has been shown that ADHD impairs major areas of life, including quality of life (QoL), social relations, family functioning, and education and occupational functioning (Danckaerts et al., 2009; Nijmeijer et al., 2008; Coghill et al., 2008; van der Kolk et al., 2014).

DSM-IV criteria (Diagnostic and Statistical Manual of Mental Disorders, 4th edition) state that a diagnosis of ADHD is only confirmed if the child exhibits a number of inattentive, impulsive and hyperactive behaviors over a period of six months, which started before the age of seven, which should be present in school and at home, and which significantly impair daily functioning (American Psychiatric Association, 2000). In practice, indeed problems in school often bring the child with ADHD to clinical attention (Loe \& Feldman, 2007). Numerous studies have reported on the association of ADHD and poorer grades, poorer reading and math standardized test scores, and increased grade retention (Loe \& Feldman, 2007; Trampush, Miller, Newcorn, \& Halperin, 2009; Rabiner, Anastopoulos, Costello, Hoyle, \& Swartzwelder, 2008; DuPaul, Weyandt, O’Dell, \& Varejao, 2009; Biederman et al., 2008). Also, children with ADHD are more likely to use special educational services than children without ADHD (Hakkaart-van Roijen et al., 2007). As several studies report on lower IQ (intelligence quotient) in children with ADHD compared to youth of the same age and gender without the disorder, it could be the case that IQ is related to the educational problems rather than specific ADHD symptoms (Biederman, Fried, Petty, Mahoney, \& Faraone, 2012). However, even when taking IQ into account, children with ADHD showed significant educational under-attainment relative to what would have been expected on their intellectual potential (Biederman et al., 2008). Therefore, it could be the case that several factors together account for the lower average education achievements in children and adolescents with ADHD. It seems fair to conclude that there is a general consensus on a certain but not precisely defined negative impact of ADHD on school outcome. However, there is no consensus on the specific cause for this impact: is it the ADHD itself that causes the impact or are underlying factors at stake?

Given these considerations, this systematic review focuses on the following question: "Is it possible to identify factors that have been demonstrated to be associated with educational and academic performance in ADHD based on the current available evidence, and if so: which factors are those?” This research will contribute to understanding the impact of ADHD on educational and academic performance and will offer insights for studies or interventions to decrease the negative impact. To our knowledge, no other systematic review has been performed on this specific topic so far.

\section{Methods}

A literature search on English-language articles was conducted using the PubMed ${ }^{\circledR}$ (Public Medline) database (biomedical literature from MEDLINE ${ }^{\circledR}$-Medical Literature Analysis and Retrieval System Online, life science journals, and online books) to gain insight in the association of ADHD and educational and academic perfor- 
mance. The search was focused on articles published in PubMed from January 2000 till the final search that was conducted on October 13th 2014.

\subsection{Guidelines Systematic Review}

Assessment of the tracked records followed the PRISMA guidelines for methodology (Preferred Reporting Items for Systematic Reviews and Meta-Analyses) (Moher, Liberati, Tetzlaff, \& Altman, 2009). PRISMA is the most often used methodology for reporting systematic reviews, expressing the aim of standardized reporting and enhancing the clarity of systematic reviews with a generic approach (Fleming, Koletsi, \& Pandis, 2014).

\subsection{Identification and Screening}

For this search, the Medical Subject Headings $\left(\mathrm{MeSH}^{\circledR}\right)$ for indexing PubMed citations were used, but no extra subheadings were selected. The key words were combined with the term "ADHD” using the PubMed Search Builder. The single MeSH term ADHD was used with selection of "Restrict to MeSH Major Topic". The following broad terms were used and a filter was used during the search on publication date (2000 onwards), and language (English): MeSH term “education” with selection of “Restrict to MeSH Major Topic”.

Specific PubMed search:

“Attention Deficit Disorder with Hyperactivity” [Majr] AND (“Education” [Majr]) AND (“2000/01/01” [PDAT]: “2014/10/13” [PDAT]) AND (“English” [Filter]).

All search results were combined into a single master Reference Manager (RM) database. References within the master RM database were transferred to Excel and then screened independently by both AvdK and MvA based on title for the following keywords to identify articles of possible relevance: “ADHD”; “Attention Deficit Hyperactivity Disorder”; “Attention-Deficit Hyperactivity Disorder”; “Attention Deficit-Hyperactivity Disorder”; “Attention Deficit/Hyperactivity Disorder”; “Attention Deficit/Hyperactivity-Disorder”; “Attention-Deficit/ HyperactivityDisorder”; accompanied with either one of the keywords:

“(Special) education(al)”; “school(ing)”; “homework”; “IQ”; “(primary/high) school”; “student(s)”; “academy’, “academic(al)”; “college”; “graduation”; “university”; “training”; “class(room)”.

Articles were then screened by abstract by two authors, again independently (AvdK and MvA). The following in- and exclusion criteria were applied: Inclusion: ADHD needed to be the major area of interest of the study, but comorbidity was not necessarily an exclusion criterion. Studies were only included if they provided data analyses. The review aimed to include explanatory articles for the relationship between ADHD and poorer educational performance. Therefore, also articles presenting outcomes of a certain class-room intervention were included, since we assumed this could provide information on beneficial factors related to ADHD and educational outcome which in turn provide information on impacting features. Articles with a focus on for example working memory and ADHD were also included, as this could provide specific information on explanatory factors for the negative impact of ADHD on school outcome. If no abstract was available, this study was included for full-text selection to be sure not to miss relevant information. Articles were excluded if the study was descriptive or an essay not containing the generation of data. Studies with the clear aim of analyzing if ADHD in fact accounts for a lower grade point average, increased school drop-out or other factual representations of worse educational outcome were excluded, since the focus of our review was on explanatory variables and not on the relationship itself. Articles describing interventions for teachers and/or parents to overcome problems related to ADHD were excluded, since we wanted to provide an answer to possible associations related to the ADHD schoolchild/student rather than the teacher or parent. Studies on abuse of medication by non-ADHD adolescents or drug-abuse by ADHD students were excluded. Articles with a focus on diagnosing ADHD in a specific setting were excluded. In this review, the snowball procedure was not applied, since the research question was not as specific as can be in a search for clinical trials, so we decided to keep the focus on the PubMed results to increase replication possibilities. Disagreement regarding eligibility was resolved through discussion and mostly by inclusion of the article for full-text review. Table 1 provides an overview of the literature search.

\subsection{Eligibility}

Articles selected for full-text screening based on screening on title and abstract were then synthesized in a qualitative way by the two researchers (AvdK and MvA). There was no disagreement on articles selected for qualita- 
Table 1. Table type styles Literature search.

\begin{tabular}{|c|c|}
\hline Literature search & Selection for inclusion based on title \\
\hline $\begin{array}{l}\text { PubMed } \\
\text { Search criteria } \\
-\quad \text { January 1st } 2000 \text { till October 13th } 2014 \\
-\quad \text { English language } \\
-\quad \text { MeSH terms: ADHD and Education }\end{array}$ & $\begin{array}{ll}\text { ADHD major area of interest + keyword } \\
- & \text { (Special) education } \\
- & \text { School(ing) } \\
- & \text { Class(room) } \\
- & \text { Homework } \\
- & \text { IQ } \\
- & \text { Student } \\
- & \text { Study } \\
- & \text { Academy } \\
- & \text { Academic } \\
- & \text { Training } \\
- & \text { Primary/high school } \\
- & \text { College } \\
- & \text { University } \\
- & \text { Graduation }\end{array}$ \\
\hline \multicolumn{2}{|c|}{ Selection for inclusion based on abstract and eligibility phase } \\
\hline 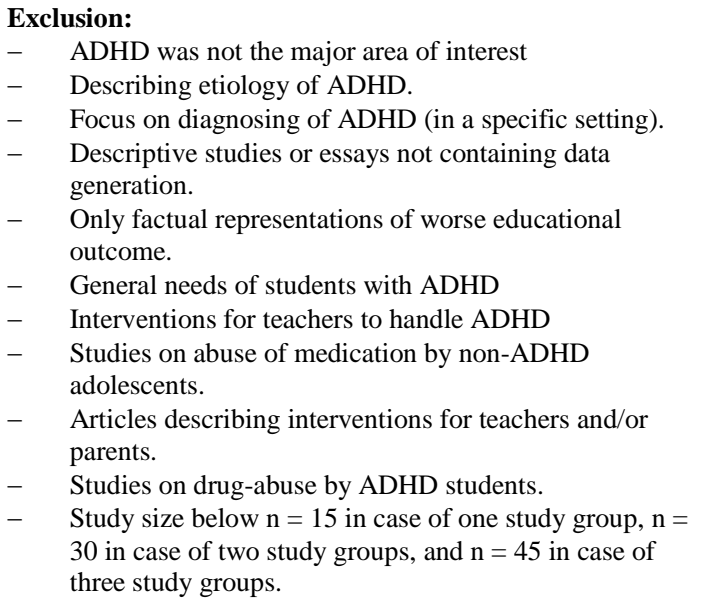 & $\begin{array}{l}\text { Inclusion: } \\
-\quad \text { ADHD as major area of interest of the study, but comorbidity } \\
\text { was not necessarily an exclusion criterion. } \\
\text { - } \quad \text { Explanatory articles for the relationship between ADHD and } \\
\text { poorer educational performance. } \\
\text { - } \quad \text { Outcomes of a certain class-room intervention were included. } \\
-\quad \text { Focus on for example working memory and ADHD. } \\
-\quad \text { If no abstract was available. }\end{array}$ \\
\hline
\end{tabular}

tive analysis. Since the validity of a systematic review has more direct practical implications, possibility for synthesis and assessment of results was based on a flowchart presented by the Finnish Institute of Occupational Health (Verbeek, Ruotsalainen, \& Hoving, 2012). Based on the flowchart, results were analyzed by means of narrative synthesis, that is, describing the results as well as possible (Verbeek et al., 2012). This method was chosen, since the various study elements (especially outcome) were not similar enough in structure between the different articles to combine results. This narrative process also provides ideas for implications for future research. The narrative approach was preferred over the levels of evidence method described by the Cochrane Back Review Group and the vote counting method, since these methods are mainly based on p-values.

There was no specific focus in this review on the way the diagnosis of ADHD was stated. This was decided, since no uniformly agreed upon diagnostic tool for ADHD exists. Therefore, no clear cut-off rule could be established regarding which diagnostic tool would be deemed valid and which would be not. In general, it is assumed that a clinical interview should be part of diagnosis to be able to incorporate ADHD symptoms and their impact, but also academic and social functioning should be assessed (Kutcher et al., 2004; Buitelaar, Wilens, Zhang, Ning, \& Feldman, 2009). However, five guidelines published by governmental organizations in Europe do not show consensus on the proper diagnostic process (Scottish Intercollegiate Guidelines Network (SIGN), 2009; Insituto superiore di sanita (ISS), 2009; Trimbos-instituut in opdracht van Landelijke Stuurgroep Multidisciplinaire Richtlijontwikkeling in de GGZ, 2005; National Institute of Health and Clinical Excellence (NICE), 2008; Arbeitsgemeinschaft ADHS (AG ADHS), 2007). Therefore, we relied on the validity of the diagnosis of ADHD as stated by the authors of the included articles.

The first data extraction included country of origin, sample size, and research question. A second table was 
constructed based on main findings, and conclusions for the articles included.

\section{Results}

The master database included 376 records, no duplicates were found. These 376 records were screened by title for relevant articles. Of these, 185 articles were screened by abstract and 35 articles were identified for inclusion in the review. Figure 1 presents the screening process in more detail. For each of the studies included in the qualitative synthesis, Table 2 displays the country of origin, the number of participants and the research question. Table 3 presents the main outcomes per included study. The articles were grouped together based on their subject, these groups were not determined beforehand in order to be as inclusive as possible, but evolved based on the content of the articles eligible for inclusion. Meta-analysis was not feasible owing to the heterogeneity in outcomes reported across all study types included in the review; however, results per study type were combined and used for concluding statements.

The 35 articles selected were based on studies executed in several countries or regions, however, the United States of America (USA) was the main source of evidence: USA $n=24$, Canada and Israel $n=2$, Netherlands, Australia, Taiwan, Spain, Italy, Belgium, Germany $n=1$, total of Europe $n=11$. Most articles reported on an ADHD group and a group of controls $(n=25)$. Results are reported based on their content and their assigned domain. Topics were articles related to training, coaching, instruction, educational consultation; educational environment; pharmacological treatment; symptoms, symptom severity and persistence of symptoms; predictive factors or associations of ADHD with academic outcomes; self-concept; or working memory or a specific skill.

\subsection{Training, Coaching, Instruction, Educational Consultation}

A total of five studies were related to this domain, three from USA and two from Israel (Gol \& Jarus, 2005; Shalev, Tsal, \& Mevorach, 2007; Dupaul et al., 2006; Curtis, Chapman, Dempsey, \& Mire, 2013; Parker, Hoffman, Sawilowsky, \& Rolands, 2013). The studies focused on the possible beneficial effect of certain types of training for school-children with ADHD ( $=4$; age 6 - 13) and college students (year: freshman to senior)

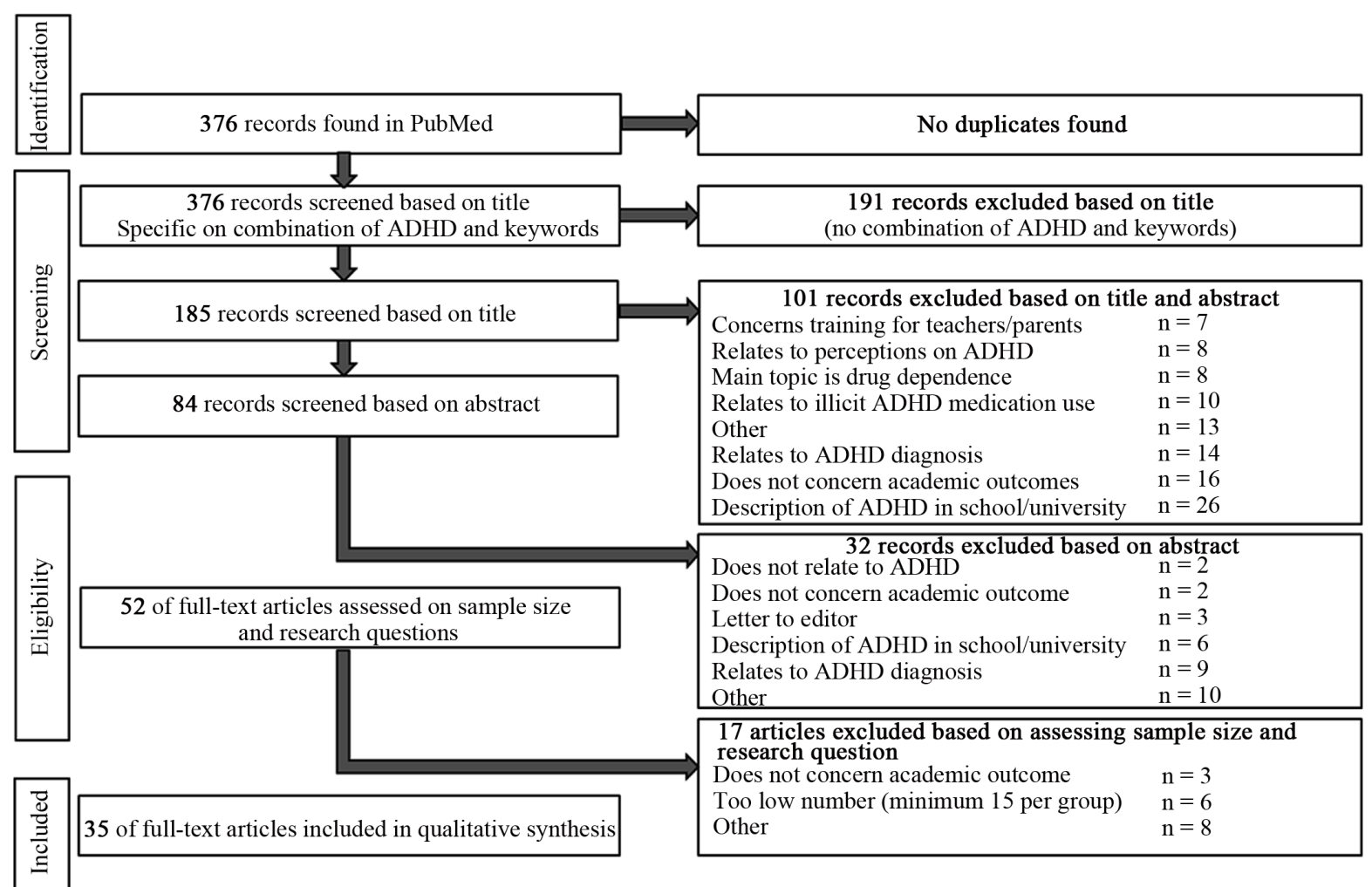

Figure 1. Flow diagram of screened and included articles. 
Table 2. Country of origin, sample size and research questions of selected articles.

\begin{tabular}{|c|c|c|c|}
\hline Country & Sample size & Research question & Reference \\
\hline \multicolumn{4}{|c|}{ Articles relating to training, coaching, instruction, educational consultation } \\
\hline USA & 175 & $\begin{array}{l}\text { What is the differential effect of two models of educational consultation (typical and } \\
\text { behavioral) on the academic functioning of sample ADHD students? }\end{array}$ & (Dupaul et al., 2006) \\
\hline USA & 26 & $\begin{array}{l}\text { - What is the classroom outcome for children with ADHD following an intervention } \\
\text { called Family Skills Training (behavioral parent training and child focused } \\
\text { self-regulation training) for ADHD-Related Symptoms? }\end{array}$ & (Curtis et al., 2013) \\
\hline USA & 19 & $\begin{array}{l}\text { - What is the effect of ADHD coaching on students' perceptions of the process they } \\
\text { - } \quad \text { used to achieve or maintain academic goals such as grade point average? } \\
\text { What benefits do students associate with coaching services? }\end{array}$ & (Parker et al., 2013) \\
\hline Israel & $\begin{array}{l}27 \text { ADHD } \\
24 \text { controls }\end{array}$ & $\begin{array}{l}\text { - What is the functioning in daily tasks of children with ADHD compared with those } \\
\text { without ADHD? } \\
\text { - What is the efficacy of occupational therapy intervention? }\end{array}$ & (Gol \& Jarus, 2005) \\
\hline Israel & $\begin{array}{l}20 \text { ADHD } \\
16 \text { controls }\end{array}$ & $\begin{array}{l}\text { - Can attention deficits of children with ADHD be ameliorated by an individualized } \\
\text { training program (exercising the attentional networks)? }\end{array}$ & (Shalev et al., 2007) \\
\hline \multicolumn{4}{|c|}{ Articles relating to educational environment or tool } \\
\hline Italy & $\begin{array}{l}27 \text { ADHD } \\
28 \text { ADHD + } \\
\text { LD } \\
29 \text { controls }\end{array}$ & $\begin{array}{l}\text { - Are three types of knowledge better acquired and retained when provided by a } \\
\text { hypermedia tool as opposed to traditional instruction? } \\
\text { Do hypermedia tools yield the same better learning outcomes (if any) both in the } \\
\text { acquisition and in the retention phase? } \\
\text { Do groups differ in knowledge assimilation according to the instructional setting to } \\
\text { which they are assigned? }\end{array}$ & $\begin{array}{l}\text { (Fabio \& Antonietti, } \\
\text { 2012) }\end{array}$ \\
\hline USA & $\begin{array}{l}19 \text { ADHD } \\
16 \text { controls }\end{array}$ & $\begin{array}{l}\text { - Are children with ADHD more affected by distractions in the virtual classroom than } \\
\text { those without ADHD? }\end{array}$ & (Adams et al., 2009) \\
\hline Belgium & $\begin{array}{l}31 \text { ADHD } \\
31 \text { controls }\end{array}$ & $\begin{array}{l}\text { - Are attention-related problems in the classroom exacerbated in children with ADHD } \\
\text { by specific class conditions? } \\
\text { - Does the teacher's supervision level influence the relation between class-context and } \\
\text { on-task behavior? }\end{array}$ & (Imeraj et al., 2013) \\
\hline Germany & $\begin{array}{l}55 \text { ADHD } \\
55 \text { controls }\end{array}$ & $\begin{array}{l}\text { - How much on-task behavior and what kind of on-task behaviors do children with } \\
\text { ADHD display? } \\
\text { - How would the lesson context affect the behavior of students with ADHD? } \\
\text { Are there differential effects of context on the behavior of students with ADHD } \\
\text { compared with matched control students? }\end{array}$ & (Lauth et al., 2006) \\
\hline \multicolumn{4}{|c|}{ Articles relating to pharmacological treatment } \\
\hline USA & $\begin{array}{l}92 \text { ADHD } \\
143 \text { controls }\end{array}$ & $\begin{array}{l}\text { - What is the relationship between ADHD medications, study habits, and academic } \\
\text { achievement of ADHD diagnosed undergraduates? }\end{array}$ & $\begin{array}{l}\text { (Advokat et al., } \\
\text { 2011) }\end{array}$ \\
\hline USA & $\begin{array}{l}24 \text { ADHD } \\
26 \text { controls }\end{array}$ & $\begin{array}{l}\text { - What is the effect of lisdexamfetamine (three doses) on ADHD symptoms and } \\
\text { executive functioning vs. placebo? }\end{array}$ & (Dupaul et al., 2012) \\
\hline USA & 45 ADHD & $\begin{array}{l}\text { What is the effect of methylphenidate on academic achievement and behavior vs. } \\
\text { placebo? }\end{array}$ & (Evans et al., 2001) \\
\hline Spain & $\begin{array}{l}34 \text { ADHD } \\
16 \text { controls }\end{array}$ & $\begin{array}{l}\text { - What is the therapeutic effect of a pharmacological intervention compared to a } \\
\text { psycho-pedagogical treatment? }\end{array}$ & $\begin{array}{l}\text { (Miranda et al., } \\
\text { 2006) }\end{array}$ \\
\hline \multicolumn{4}{|c|}{ Articles relating to symptomatology, symptom severity and persistence of symptoms } \\
\hline USA & 2844 ADHD & $\begin{array}{l}\text { - What is the importance of acknowledging subtype symptoms in outcomes for children } \\
\text { with ADHD as associated with interventions across time? }\end{array}$ & $\begin{array}{c}\text { (Barnard et al., } \\
\text { 2010) }\end{array}$ \\
\hline USA & $\begin{array}{l}326 \text { ADHD } \\
213 \text { controls }\end{array}$ & $\begin{array}{l}\text { - What is the relationship between attendance and academic Grade Point Average? } \\
\text { - Does symptom severity predict poorer outcomes within the ADHD group above and } \\
\text { beyond the contribution of IQ and parental education? }\end{array}$ & (Kent et al., 2011) \\
\hline USA & $\begin{array}{l}147 \text { USA } \\
273 \text { China }\end{array}$ & $\begin{array}{l}\text { - What is the relationship between ADHD symptomatology and academic and social } \\
\text { adjustment to college, self-confidence, and study skills? } \\
\text { - What is the separate influence of inattentive and hyperactive symptoms, while } \\
\text { controlling for depression, which may affect the ability to pay attention? }\end{array}$ & $\begin{array}{l}\text { (Norvilitis et al., } \\
\text { 2010) }\end{array}$ \\
\hline
\end{tabular}




\section{Continued}

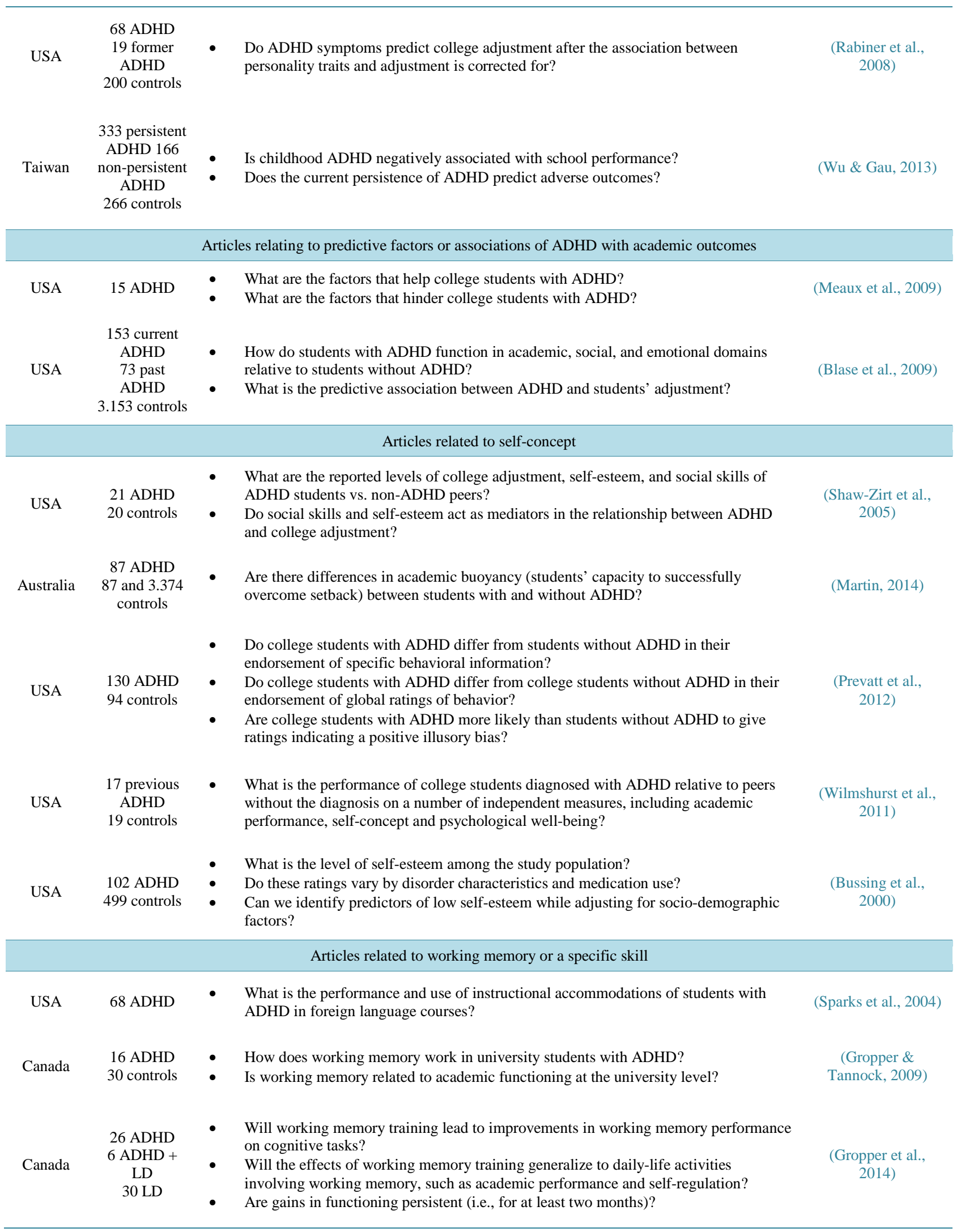




\begin{tabular}{|c|c|c|c|}
\hline \multicolumn{4}{|c|}{ Continued } \\
\hline USA & $\begin{array}{l}44 \text { ADHD } \\
42 \text { controls }\end{array}$ & - $\quad$ Auditory and visual-spatial working memory: what effect does distraction have? & $\begin{array}{l}\text { (Lineweaver et al., } \\
\text { 2012) }\end{array}$ \\
\hline USA & $\begin{array}{l}24 \text { ADHD } \\
24 \text { controls }\end{array}$ & $\begin{array}{l}\text { - What is the ability of ADHD adults to perform a visual cancellation task compared } \\
\text { with health controls? }\end{array}$ & (Jones et al., 2008) \\
\hline USA & $\begin{array}{l}20 \text { ADHD } \\
20 \text { controls }\end{array}$ & - What are time estimation abilities of college students with and without ADHD? & $\begin{array}{l}\text { (Prevatt et al., } \\
\text { 2011) }\end{array}$ \\
\hline NL & 62 ADHD & $\begin{array}{l}\text { - Does computerized working memory training with game elements enhance motivation } \\
\text { and training efficacy in children with ADHD vs. standard working memory training? }\end{array}$ & (Prins et al., 2011) \\
\hline USA & $\begin{array}{l}31 \mathrm{ADHD} \\
27 \text { controls }\end{array}$ & - What is the effect of ADHD on written expression compared to a control group? & $\begin{array}{l}\text { (Semrud-Clikeman } \\
\text { \& Harder, 2011) }\end{array}$ \\
\hline USA & $\begin{array}{c}14 \text { ADHD } \\
42 \text { ADHD + } \\
\text { LD } \\
16 \text { LD }\end{array}$ & $\begin{array}{l}\text { - Is explanatory style predictive of success as measured by Grade Point Average for } \\
\text { college students with learning disorder and attention disorders? }\end{array}$ & $\begin{array}{l}\text { (Shmulsky \& } \\
\text { Gobbo, 2007) }\end{array}$ \\
\hline
\end{tabular}

USA: United states of America; NL: The Netherlands.

(Parker et al., 2013). All five studies reported on beneficial effects of training, consultation or coaching on academic functioning. Effects were reported for specific tasks (math or reading), but also for the basic characteristics of ADHD related to externalizing behavior and attention problems with the largest influence on attention problems. Amongst others, coaching helped to be more self-regulated (ability to control one's emotions, behavior, and desires in the face of external demands), which was reported by students (college sample), teachers (children with ADHD showed better motivation and study skills) and parents (reduction in symptoms of inattentiveness). So, training could improve attention in school and account for more self-regulated behavior.

\subsection{Educational Environment or Tool}

Four studies reported on educational environment or a tool used to deliver knowledge to either an ADHD or a control group (Origin Italy, USA, Belgium and Germany; respondent’s age 6 - 14 years) (Fabio \& Antonietti, 2012; Adams, Finn, Moes, Flannery, \& Rizzo, 2009; Imeraj et al., 2013; Lauth, Heubeck, \& Mackowiak, 2006). Topics related to acquiring and attaining knowledge, distraction, and behavior in general in relation to class conditions (class structures and academic content types). Children with ADHD were more distracted compared to controls and had a shorter on-task span during academic tasks (mathematics, language, and sciences). However, this shorter on-task span was not present during music and arts. Also, learning via a computer-based service yielded better results compared to traditional instruction and could specifically improve outcomes related to attention deficits. Another environmental outcome was better functioning while working in a small group compared to individual tasks or whole class work. Individual task work accounted for more problems than whole class work.

\subsection{Pharmacological Treatment}

Four studies were related to ADHD and pharmacological treatment, three were originated in USA, one in Spain (Miranda, Jarque, \& Rosel, 2006; Evans et al., 2001; Dupaul et al., 2012; Advokat, Lane, \& Luo, 2011). Studies were focused on the effect of different types of pharmacotherapy (stimulants and non-stimulants) on study habits, academic achievement in general, ADHD symptoms and executive functioning. One of the studies was a doubleblind, placebo-controlled study reporting a positive effect on symptom relieve (inattention and hyperactivity), but this study was not specifically designed to report on academic achievements (Dupaul et al., 2012). The other studies reported beneficial effects of pharmacological treatment on concentration, planning, organization, executive functioning and working memory. More specifically to studying, effects on note-taking quality and homework completion were reported.

\subsection{Symptoms, Symptom Severity and Persistence of Symptoms}

The DSM-IV divides the symptoms of ADHD into two groups: symptoms of inattention and symptoms of hyperactivity-impulsivity (American Psychiatric Association, 2000). Five studies reported on subtype symptoms, 
Table 3. Outcomes and reported associations of selected articles.

\section{Main outcome}

- The findings support academic consultation to enhance academic functioning in children with ADHD.

- $\quad$ Large effect sizes ( $>0.80$ ): math calculation, math fluency, reading fluency and passage comprehension.

(Dupaul et al., 2006)

- $\quad$ Results indicated significant classroom improvements for externalizing behaviors and attention problems with medium and large main effects.

(Curtis et al., 2013)

- $\quad$ Significant results were observed for changes in ADHD symptoms of inattention due to family training $(p<0.01)$.

- $\quad$ Students were harmonious in their belief of coaching improving how they worked on academic goals.

- $\quad$ Coaching helped to be more self-regulated: to set more realistic and specific goals, use effective time management, be able to avoid distraction in class).

- Children with ADHD improved after a social skills training aiming to improve occupational performance and no longer differed from the children without ADHD $(p<0.008)$.

- Difficulties were related to: energy, time, and adaptation, following instructions and terminating the task, difficulties in organizing actions, talking too frequently.

- The participants showed improvement in non-trained measures of reading comprehension, and passage copying as well as a reduction of reports of inattentiveness $(p<0.05)$.

- Children with ADHD received a computerized attentional training program composed to activate sustained, executive and selective attention, and orienting of attention.

\section{Articles relating to educational environment or tool}

- Hypermedia instruction (computer-based devices designed to promote learning in educational settings) produced better learning outcomes than traditional instruction.

(Fabio \& Antonietti, 2012)

(Adams et al., 2009)

- Children with ADHD were more affected by distractions in the virtual reality classroom while performing a continuous performance task than those without ADHD (non-significant).

- Children with ADHD were significantly less on-task than controls during individual work and whole class group teaching, but not during small group work.

- Children with ADHD had significantly shorter on-task span during academic tasks (mathematics, language, and sciences), but not during music and arts.

- $\quad$ ADHD students displayed more problems of actively disruptive behavior across classroom contexts $(p<0.01)$.

- $\quad$ More disruptive behavior was observed during individual silent work compared with normal classroom teaching.

\section{Articles relating to pharmacological treatment}

- $\quad$ ADHD students using stimulant medication said the drugs helped them concentrate and organize better.

- Lisdexamfetamine was associated with large reductions in ADHD symptoms and improvement in executive functioning.

- Linear lisdexamfetamine effects were found for specific aspects of executive functioning related to task management, planning, organization, study skills, and working memory.

- $\quad$ Data showed significant improvement of methylphenidate on academic measures.

- $\quad$ Note-taking quality, written language usage and productivity, on-task and disruptive behavior and homework completion.

- Both medication and pedagogical interventions were effective for reducing the main symptoms of ADHD (inattention and hyperactivity).

\section{Articles relating to symptomatology, symptom severity and persistence of symptoms}

- There are significant differences in academic achievement according to long-term stimulant treatment status within each subtype symptom class (over a period of 4 years).

- Associations between receiving stimulant treatment and academic achievement were inattentive: 0.21 ; hyperactive-impulsive: 0.11 ; and combined class: 0.38 .

- Adolescents with ADHD completed and turned in a significantly lower percentage of assignments were significantly less likely to be working up to their potential.

- Baseline symptom severity of ADHD, oppositional defiant disorder and conduct disorder for adolescents with ADHD were not significant predictors of for grade point average, attendance, drop-out, or class placement.

- IQ was significantly lower in the ADHD group (102 vs. $111 ; p<0.001)$, they were more absent $(p<0.01)$, and were more tardy $(p<0.01)$.

- For academic for grade point average, R2 values were as follows: group only $=0.80$, IQ only $=0.78$, parent education only $=0.78$, and full model $=0.88$.
(Advokat et al., 2011)

(Imeraj et al., 2013)

(Lauth et al., 2006)

(Dupaul et al., 2012)

(Evans et al., 2001)

(Miranda et al., 2006)

(Barnard et al., 2010)

(Kent et al., 2011) 


\section{Continued}

- $\quad$ Higher levels of inattentive symptoms were related to decreased academic and social adjustment, career decision-making, self-efficacy, and poorer study.

- Depression itself clearly plays a role in college students' adjustment, but this appears to be independent of the role of ADHD symptomatology.

- Higher levels of ADHD were associated with higher levels of depression $(p<0.001)$, depression significantly predicted social adjustment $(p<0.001)$.

- $\quad$ Higher levels of ADHD were related to lower levels of academic adjustment $(p<0.01)$, poorer study skills ( $p<$ $0.001)$, and lower levels of social adjustment to college $(p=0.31)$.

- $\quad$ Students with ADHD reported more academic concerns and depressive symptoms. This was explained by higher rates of inattention among students with ADHD and was unrelated to hyperactivity.

- $\quad$ Students currently diagnosed with ADHD reported more concerns about their academic performance and higher rates of depressive symptoms (effect size 0.48 and 037 ).

- Inattentive symptoms remained a significant predictor of depressive symptoms after personality factors were controlled for $p<0.001$.

- The most consistent correlates for all domains of impaired school functioning were youth reported and mother reported inattention symptoms and increased age.

- $\quad$ Both ADHD groups (persistent and non-persistent ADHD) had lower full-scale IQ $(p<0.001)$.

Articles relating to predictive factors or associations of ADHD with academic outcomes

- Identification of three global themes: gaining insight about ADHD, managing life and utilizing sources of support. Each global theme contains factors that hinder, as well as factors that help the college student with ADHD.

- $\quad$ Persistent symptoms created challenges to academic success because of poor time management and organization skills, difficulty staying focused, failure to complete work on time, poor motivation, poor reading and study skills and difficulty sleeping and getting up in the morning.

- $\quad$ Relative to other students, those with self-reported ADHD reported more academic concerns, depressive symptoms, social concerns, and emotional instability.

- $\quad$ For groups with current and past symptoms, inattention was present to a larger extend compared to hyperactivity (1.23/0.88 vs. $1.00 / 0.73)$.

$$
\text { Articles related to self-concept }
$$

- The results suggest that the relation between ADHD and college adjustment is partially mediated by self-reported levels of self-esteem $(p=0.001)$.

- There were significant main effects for group $(p=0.001)$ and gender $(p<0.03)$. Female participants in general reported better social skills than male participants do.

(Shaw-Zirt et al., 2005)

(Blase et al., 2009)

- There is a significant association between academic buoyancy (students' capacity to successfully overcome setback and challenge) and outcomes for students with ADHD.

- For the ADHD and non-ADHD groups, academic buoyancy is positively correlated with achievement (0.19 and 0.13 ) and engagement (0.38 and 0.35).

- $\quad$ ADHD participants were significantly more likely to engage in the positive illusory bias (effect of people thinking they are "better than average") for work skills ratings ( $p=0.005)$.

(Prevatt et al., 2012)

- $\quad$ Students with ADHD reported significantly higher paternal support than controls $(p<0.04)$ who reported significantly greater support from friends $(p<0.02)$.

- $\quad$ There was a significant effect for gender for grade point average, (females scoring higher than males; $p<0.022$ ).

- For students with ADHD, environmental mastery (competence in managing their environment, making effective use of available opportunities) significantly predicted total self-concept $(p<0.009)$.

- $\quad$ Children with ADHD criteria had significantly lower self-esteem $(p<0.05)$.

- Total self-esteem scores varied significantly by type of associated disorders and were lowest for children with comorbid internalizing symptoms $(p<0.001)$. ADHD alone: $\mathrm{n}=52$; Piers-Harris Self-Concept Scale (PHSCS) 65.4 - ADHD + externalizing: $\mathrm{n}=$ 40; PHSCS 61.9 - ADHD + internalizing: $\mathrm{n}=18$; PHSCS 46.8 - ADHD + externalizing + internalizing: $\mathrm{n}=18$; PHSCS 47.7.

\section{Articles related to working memory or a specific academic skill}

- Two thirds of the students with ADHD passed all of their foreign language courses without the use of instructional accommodations (for example for example extended time).

(Wilmshurst et al., 2011)

- $\quad$ The ADHD group displayed significant weaknesses on auditory-verbal working memory tasks.

- Within the entire sample, there was a significant relationship between for grade point average and auditory-verbal working memory $(\mathrm{r}=0.405, p<0.01)$.
(Sparks et al., 2004)

(Gropper \& Tannock, 2009) 


\section{Continued}

- $\quad$ Participants receiving computerized working memory training showed significantly greater improvements and self-reported fewer ADHD symptoms and cognitive failures.

- $\quad$ Students with ADHD demonstrated worse auditory working memory.

(Gropper et al., 2014)

(Lineweaver et al., 2012)

(Jones et al., 2008)

(Prevatt et al., 2011)

(Prins et al., 2011)

(Semrud-Clikeman \& Harder, 2011)

(Shmulsky \& Gobbo, 2007)

symptom severity, and persistence of symptoms (Barnard, Stevens, To, Lan, \& Mulsow, 2010; Kent et al., 2011; Norvilitis, Sun, \& Zhang, 2010; Rabiner et al., 2008; Wu \& Gau, 2013). Four studies were USA based; one was executed in Taiwan (Wu \& Gau, 2013). One study was both related to pharmacological treatment (specifically with a stimulant) and subtype symptom class (Barnard et al., 2010). The result was that especially inattentiveness was related to worse academic outcomes with effects on self-efficacy and depressive symptoms. Depressive symptoms independently turned out to be related to college and social adjustment. Baseline symptom severity turned out not to be significant predictors for grade point average, class attendance, or drop-out, although the ADHD group was significantly more absent and tardy compared to controls. Two studies reported on IQ and concluded on a significantly lower IQ for ADHD students (Kent et al., 2011; Wu \& Gau, 2013).

\subsection{Predictive Factors or Associations of ADHD with Academic Outcomes}

Two USA studies related to factors associated with ADHD and problems in college specifically (Meaux, Green, \& Broussard, 2009; Blase et al., 2009). One study also searched for factors that can help students with ADHD, although only 15 respondents were included in this qualitative study (Meaux et al., 2009). Inattention turned out to be present to a larger extent compared to hyperactivity. Students with ADHD reported challenges to academic success due to difficulties in focus, completing work in time and poorer time management and organization skills. Coping with the ADHD and managing challenges in everyday life were also mentioned by the ADHD group related to difficulties with academic success. Depressive symptoms and emotional instability were present to a larger extent in the ADHD population.

\subsection{Self-Concept}

One's self-concept (also called self-construction, self-identity, self-perspective or self-structure) is a collection of beliefs about oneself that includes elements such as academic performance gender roles, sexuality and racial identity and accounts for the regard for oneself as a person (Wilmshurst, Peele, \& Wilmshurst, 2011). Four studies from USA and one from Australia were focused on studies related to (predictors of low) self-esteem, ratings of own behavior, and psychological well-being (Shaw-Zirt, Popali-Lehane, Chaplin, \& Bergman, 2005; Martin, 2014; Prevatt et al., 2012; Wilmshurst et al., 2011; Bussing, Zima, \& Perwien, 2000). All four studies were based on an ADHD group compared to controls. It is suggested that reported levels of self-esteem mediates the relation between ADHD and college adjustment. Next to that, children with ADHD reported significantly lower self-esteem and scores were lowest for children with ADHD and comorbid internalizing problems, especially in the areas of anxiety and popularity, although females tend to report better social skills. Medication use was not a predictor of lower self-esteem scores. Students' capacity to successfully overcome setback and challenge (academic buoyancy) was significantly associated with outcomes for students with ADHD and also academic buoyancy was positively correlated with academic achievement and engagement. On the other hand, one study reported that students with ADHD were more engaged in the bias of thinking they are "better than average" 
(positive illusory bias), which is in contrast with lower self-esteem.

\subsection{Working Memory or a Specific Skill}

Working memory refers to the ability to temporarily maintain and manipulate information necessary for achieving a certain goal (Gropper, Gotlieb, Kronitz, \& Tannock, 2014). The largest group of studies $(n=9)$ reported on working memory or related to time estimation, explanatory style, or written expression (Sparks, Javorsky, \& Philips, 2004; Gropper et al., 2014; Gropper \& Tannock, 2009; Lineweaver et al., 2012; Jones, Craver-Lemley, \& Barrett, 2008; Prevatt, Proctor, Baker, Garrett, \& Yelland, 2011; Prins, Dovis, Ponsioen, ten, \& van der Oord, 2011; Semrud-Clikeman \& Harder, 2011; Shmulsky \& Gobbo, 2007). ADHD students display significant weaknesses in the auditory-verbal working memory tasks compared to controls and were significantly worse in time estimation abilities. When using computer-based working memory training with game elements, ADHD children showed better training performance, and better working memory outcomes compared to regular computer-based training, although students with ADHD trained with computerized working memory training also showed significantly greater improvements and self-reported fewer ADHD symptoms and cognitive failures. Executive function, written expression and passing of foreign language courses did not relate to significant differences between ADHD and control students.

\section{Discussion}

This systematic review focused on the question: Is it possible to identify factors that have been demonstrated to be associated with educational and academic performance in ADHD based on the current available evidence, and if so: which factors are those? This question was raised, since based on available literature it can be concluded that there is a certain negative impact of ADHD on school outcome, but without consensus on the specific cause for this impact. The study focused on articles presenting results of data-based analysis related to the main topic ADHD and specific keywords related to education. A total of 35 studies met the eligibility criteria for this analysis. They were analyzed by means of narrative synthesis since outcomes were too heterogeneous to combine results. The articles related to seven different domains; educational training, educational environment; pharmacological treatment; symptomatology, associations of ADHD with academic outcomes, self-concept, and specific skills.

One main finding stands out when trying to answer the question: is it the ADHD itself that causes the impact on educational achievements or are underlying factors at stake? When reviewing all included studies, the main source of problems seems to be associated with the inattentive symptoms of ADHD and not so much in the hyperactive or impulsive symptoms. This outcome is different than expected, since hyperactive symptoms, which are more prominently pronounced, are usually the main cause of referral to clinical evaluation, probably since teachers and other students experience burden of particularly those symptoms (Skounti, Philalithis, \& Galanakis, 2007; Polanczyk et al., 2007). It also has been reported that the prevalence of the hyperactive-impulsive subtype decreases when children get older, whereas the inattentive subtype increases (Nolan, Gadow, \& Sprafkin, 2001). This is a very important finding in the light of the results of this systematic review. The ongoing impact of ADHD, which frequently maintains into adulthood, seems to be associated with inattentiveness and according to our review, it is the inattentiveness that seems to be associated with educational performance. This yields important information as to which areas to target when it comes to opting for clinical or non-clinical interventions in order to mitigate the impact of the ADHD.

Studies relating to educational environment and content showed that ADHD children in general had a shorter on-task span, but were better able to perform in small group work, in music and art classes and in learning via a computer-based service, especially when including game-elements. ADHD students showed weaknesses in the auditory-verbal working memory. Studies reporting on training and coaching concluded on beneficial effects of different training types, with especially positive effects on inattentive symptoms and related behavior. Pharmacological treatment showed beneficial effects on concentration, planning, organization, executive functioning and working memory. Problems in school can also be related to occupational achievements, since individuals that are diagnosed with ADHD often continue to have problems during adulthood and into their working life (Barkley, Fischer, Smallish, \& Fletcher, 2002). The negative impact of ADHD on work performance of adults has been demonstrated in extensive surveys (de Graaf et al., 2008; Kessler et al., 2005). ADHD is associated with 22 - 35 annual days of lost role performance compared to respondents without ADHD related to decre- 
ments in work performance or absence (de Graaf et al., 2008; Kessler et al., 2005). These problems in working life might be mitigated when proper help is offered when in school.

A factor that might play a role in the large impact of inattentive symptoms on educational and academic outcomes is the existence of comorbidities. In ADHD, symptom overlap or comorbidity with other conditions is the rule rather than the exception (Rommelse et al., 2009; Gillberg et al., 2004). In our review, ADHD was required to be the major area of interest of the study, but comorbidity was not necessarily an exclusion criterion. The review concluded that the inattentiveness also affected self-efficacy and depressive symptoms which in turn influence the relation between ADHD and educational and academic outcome. Also, children with ADHD are at high risk of adolescent depression (Chronis-Tuscano et al., 2010). Next to the influence of inattentiveness on school outcome, our review found that depressive symptoms also influence the effect of ADHD and academic outcome. Another phenomenon frequently mentioned in this respect that could be involved in comorbidity and academic outcome is stigmatization (DosReis, Barksdale, Sherman, Maloney, \& Charach, 2010). Stigma can have a harmful effect on social functioning and can increase depressive symptoms (Shaw-Zirt et al., 2005). Stigmatization can be obvious and direct, for example when a classmate makes a negative remark about the ADHD (DosReis et al., 2010). Our review showed that social functioning of ADHD children improved after a social skills training and therefore potentially could reduce the harmful effect of stigmatization. Next, our review found that female participants in general reported better social skills than male participants do. Taking this into account, stigmatization might affect boys more than girls, due to more obvious symptoms (hyperactivity) and having less social skills to begin with.

As with all research, the value of a systematic review depends on what was done, what was found, what was reported and what was concluded (Moher et al., 2009). A limitation of this review is related to its sources: selection of patients is not always clear. In our review, there was no specific focus on the method of diagnosing ADHD. This was decided upon, since no clear cut-of could be established of which ADHD diagnostic would be included. We choose not to focus on this specific aspect of the studies, since no evidence would have been left for inclusion in this review due to the lack of a uniform method of diagnosis. We therefore had to rely on the investigators' discretion in guaranteeing the validity of the diagnosis of ADHD in their subjects. However, future studies might choose to specifically focus on method of diagnosing ADHD and the influence on educational outcomes. As described, comorbidity is often present in children and adolescents with ADHD. In the articles included in our review, we did not specifically focus on the existence of comorbidity or the moderating effect that comorbidity could have. Finally, treatment status of respondents was not always reported (adequately), so the establishment of a clear relationship between impact of ADHD and the mitigation by certain treatment types cannot properly be made.

This review highlights areas of interest for future studies. As school systems and referring systems differ between countries, it is recommendable to perform studies on the effect of ADHD in several countries at the same time. Finally, more longitudinal studies might contribute a lot to the knowledge on the effect of ADHD on education and academic performance and occupational performance later in life.

\section{Conclusion}

The main association of educational and academic problems seems to be the inattentive symptoms (or subtype) of ADHD. This outcome is different than expected, since hyperactive symptoms are more prominently pronounced. The answer to the question if the ADHD itself causes the impact on negative educational outcomes or that underlying factors at stake is that both seem to be true. The inattentive symptoms of ADHD tend to be associated with most of the problems experienced, but also other factors like educational environment, depression and self-concept seem to play a role. Since ADHD is considered a treatable disorder the negative impact on educational and academic outcome has the potential to be mitigated if patients are diagnosed and treated adequately (Weiss, Gadow, \& Wasdell, 2006; Matza et al., 2004; Barkley, 2008). More important for the patients at stake, next to a relief of clinical symptoms, proper help when diagnosed with ADHD might also help children and adults to achieve educational goals that now are sometimes out of reach. Especially, overcoming negative outcomes of inattentiveness should be a major focus, next to improvement of social skills to deal with everyday life in schools (especially in males). Simple interventions could be found in environmental changes, since children with ADHD showed better functioning while working in a small group. Lower education outcome in its turn will also have an economic impact in the end (Biederman et al., 2008). More attention and support should be 
given to ADHD students to improve their chances in society and the economic influence of ADHD based on lower academic levels should be an important foundation when it comes to allocating resources to support ADHD patients.

\section{References}

Adams, R., Finn, P., Moes, E., Flannery, K., \& Rizzo, A. S. (2009). Distractibility in Attention/Deficit/Hyperactivity Disorder (ADHD): The Virtual Reality Classroom. Child Neuropsychology, 15, 120-135. http://dx.doi.org/10.1080/09297040802169077

Advokat, C., Lane, S. M., \& Luo, C. (2011). College Students with and without ADHD: Comparison of Self-Report of Medication Usage, Study Habits, and Academic Achievement. Journal of Attention Disorders, 15, 656-666. http://dx.doi.org/10.1177/1087054710371168

American Psychiatric Association (2000). Diagnostic and Statistical Manual of Mental Disorders (4th ed). Text Revision (DSM-IV-TR). (Vols. Revised 4th ed.), Washington DC.

Arbeitsgemeinschaft ADHS (AG ADHS) (2007). ADHS bei Kindern und Jugendlichen.

Barkley, R. A. (2008). Global issues related to the Impact of Untreated Attention-Deficit/Hyperactivity Disorder from Childhood to young Adulthood. Postgraduate Medicine, 120, 48-59. http://dx.doi.org/10.3810/pgm.2008.09.1907

Barkley, R. A., Fischer, M., Smallish, L., \& Fletcher, K. (2002). The Persistence of Attention-Deficit/Hyperactivity Disorder into young Adulthood as a function of Reporting Source and definition of Disorder. Journal of Abnormal Psychology, 111, 279-289. http://dx.doi.org/10.1037/0021-843X.111.2.279

Barnard, L., Stevens, T., To, Y. M., Lan, W. Y., \& Mulsow, M. (2010). The importance of ADHD Subtype Classification for Educational applications of DSM-V. Journal of Attention Disorders, 13, 573-583. http://dx.doi.org/10.1177/1087054708326433

Biederman, J., Fried, R., Petty, C., Mahoney, L., \& Faraone, S. V. (2012). An Examination of the Impact of Attention-Deficit Hyperactivity Disorder on IQ: A Large Controlled Family-Based Analysis. The Canadian Journal of Psychiatry, 57, 608-616.

Biederman, J., Petty, C. R., Fried, R., Kaiser, R., Dolan, C. R., Schoenfeld, S. et al. (2008). Educational and Occupational Underattainment in Adults with Attention-Deficit/Hyperactivity Disorder: a Controlled Study. Journal of Clinical Psychiatry, 69, 1217-1222. http://dx.doi.org/10.4088/JCP.v69n0803

Blase, S. L., Gilbert, A. N., Anastopoulos, A. D., Costello, E. J., Hoyle, R. H., Swartzwelder, H. S. et al. (2009). Self-reported ADHD and Adjustment in College: Cross-Sectional and Longitudinal Findings. Journal of Attention Disorders, 13, 297-309. http://dx.doi.org/10.1177/1087054709334446

Buitelaar, J. K., Wilens, T. E., Zhang, S., Ning, Y., \& Feldman, P. D. (2009). Comparison of Symptomatic versus Functional Changes in Children and Adolescents with ADHD during Randomized, Double-Blind Treatment with Psychostimulants, Atomoxetine, or Placebo. Journal of Child Psychology and Psychiatry, 50, 335-342. http://dx.doi.org/10.1111/j.1469-7610.2008.01960.x

Bussing, R., Zima, B. T., \& Perwien, A. R. (2000). Self-Esteem in Special Education Children with ADHD: Relationship to Disorder Characteristics and Medication Use. Journal of Child Psychology and Psychiatry, 39, 1260-1269. http://dx.doi.org/10.1097/00004583-200010000-00013

Chronis-Tuscano, A., Molina, B. S., Pelham, W. E., Applegate, B., Dahlke, A., Overmyer, M. et al. (2010). Very Early Predictors of Adolescent Depression and Suicide Attempts in Children with Attention-Deficit/Hyperactivity Disorder. Archives of General Psychiatry, 67, 1044-1051. http://dx.doi.org/10.1001/archgenpsychiatry.2010.127

Coghill, D., Soutullo, C., d’Aubuisson, C., Preuss, U., Lindback, T., Silverberg, M. et al. (2008). Impact of Attention-Deficit/Hyperactivity Disorder on the Patient and Family: Results from a European Survey. Child and Adolescent Psychiatry and Mental Health, 2, 31. http://dx.doi.org/10.1186/1753-2000-2-31

Curtis, D. F., Chapman, S., Dempsey, J., \& Mire, S. (2013). Classroom Changes in ADHD Symptoms Following ClinicBased Behavior Therapy. Journal of Clinical Psychology in Medical Settings, 20, 114-122. http://dx.doi.org/10.1007/s10880-012-9307-2

Danckaerts, M., Sonuga-Barke, E. J., Banaschewski, T., Buitelaar, J., Dopfner, M., Hollis, C. et al. (2009). The Quality of Life of Children with Attention Deficit/Hyperactivity Disorder: A Systematic Review. European Child \& Adolescent Psychiatry, 19, 83-105.

De Graaf, R., Kessler, R. C., Fayyad, J., Alonso, J., Angermeyer, M., Borges, G. et al. (2008). The Prevalence and Effects of Adult Attention-Deficit/Hyperactivity Disorder (ADHD) on the Performance of Workers: Results from the WHO World Mental Health Survey Initiative. Occupational and Environmental Medicine, 65, 835-842. http://dx.doi.org/10.1136/oem.2007.038448 
DosReis, S., Barksdale, C. L., Sherman, A., Maloney, K., \& Charach, A. (2010). Stigmatizing Experiences of Parents of Children with a New Diagnosis of ADHD. Psychiatric Services, 61, 811-816. http://dx.doi.org/10.1176/ps.2010.61.8.811

Dupaul, G. J., Jitendra, A. K., Volpe, R. J., Tresco, K. E., Lutz, J. G., Vile Junod, R. E. et al. (2006). Consultation-Based Academic Interventions for Children with ADHD: Effects on Reading and Mathematics Achievement. Journal of Abnormal Child Psychology, 34, 635-648. http://dx.doi.org/10.1007/s10802-006-9046-7

DuPaul, G. J., Weyandt, L. L., O’Dell, S. M., \& Varejao, M. (2009). College Students with ADHD: Current Status and Future Directions. Journal of Attention Disorders, 13, 234-250. http://dx.doi.org/10.1177/1087054709340650

Dupaul, G. J., Weyandt, L. L., Rossi, J. S., Vilardo, B. A., O’Dell, S. M., Carson, K. M. et al. (2012). Double-Blind, Placebo-Controlled, Crossover Study of the Efficacy and Safety of Lisdexamfetamine Dimesylate in College Students with ADHD. Journal of Attention Disorders, 16, 202-220. http://dx.doi.org/10.1177/1087054711427299

Evans, S. W., Pelham, W. E., Smith, B. H., Bukstein, O., Gnagy, E. M., Greiner, A. R. et al. (2001). Dose-Response Effects of Methylphenidate on Ecologically Valid Measures of Academic Performance and Classroom Behavior in Adolescents with ADHD. Experimental and Clinical Psychopharmacology, 9, 163-175. http://dx.doi.org/10.1037/1064-1297.9.2.163

Fabio, R. A., \& Antonietti, A. (2012). Effects of Hypermedia Instruction on Declarative, Conditional and Procedural Knowledge in ADHD Students. Research in Developmental Disabilities, 33, 2028-2039. http://dx.doi.org/10.1016/j.ridd.2012.04.018

Faraone, S. V., Biederman, J., \& Mick, E. (2006). The Age-Dependent Decline of Attention Deficit Hyperactivity Disorder: A Meta-Analysis of Follow-Up Studies. Psychological Medicine, 36, 159-165. http://dx.doi.org/10.1017/S003329170500471X

Fleming, P. S., Koletsi, D., \& Pandis, N. (2014). Blinded by PRISMA: Are Systematic Reviewers Focusing on PRISMA and Ignoring Other Guidelines? PloS ONE, 9, e96407. http://dx.doi.org/10.1371/journal.pone.0096407

Gillberg, C., Gillberg, I. C., Rasmussen, P., Kadesjo, B., Soderstrom, H., Rastam, M. et al. (2004). Co-Existing Disorders in ADHD-Implications for Diagnosis and Intervention. European Child \& Adolescent Psychiatry, 13, I80-I92. http://dx.doi.org/10.1007/s00787-004-1008-4

Gol, D., \& Jarus, T. (2005). Effect of a Social Skills Training Group on Everyday Activities of Children with Attention-Deficit-Hyperactivity Disorder. Developmental Medicine Child Neurology, 47, 539-545. http://dx.doi.org/10.1017/S0012162205001052

Goodman, D. M., \& Livingston, E. H. (2013). JAMA Patient Page. Attention-Deficit/Hyperactivity Disorder. The Journal of the American Medical Association, 309, 1843. http://dx.doi.org/10.1001/jama.2013.803

Gropper, R. J., \& Tannock, R. (2009). A Pilot Study of Working Memory and Academic Achievement in College Students with ADHD. Journal of Attention Disorders, 12, 574-581. http://dx.doi.org/10.1177/1087054708320390

Gropper, R. J., Gotlieb, H., Kronitz, R., \& Tannock, R. (2014). Working Memory Training in College Students with ADHD or LD. Journal of Attention Disorders, 18, 331-345. http://dx.doi.org/10.1177/1087054713516490

Hakkaart-van Roijen, L., Zwirs, B. W., Bouwmans, C., Tan, S. S., Schulpen, T. W., Vlasveld, L. et al. (2007). Societal Costs and Quality of Life of Children Suffering from Attention Deficient Hyperactivity Disorder (ADHD). European Child \& Adolescent Psychiatry, 16, 316-326. http://dx.doi.org/10.1007/s00787-007-0603-6

Imeraj, L., Antrop, I., Sonuga-Barke, E., Deboutte, D., Deschepper, E., Bal, S. et al. (2013). The Impact of Instructional Context on Classroom On-Task Behavior: A Matched Comparison of Children with ADHD and Non-ADHD Classmates. Journal of School Psychology, 51, 487-498. http://dx.doi.org/10.1016/j.jsp.2013.05.004

Insituto superiore di sanita (ISS) (2009). Protocollo diagnostico e therapeutico della sindrome da imperattivita e deficit di attenzione per il registro nationale ADHD.

Jones, K. E., Craver-Lemley, C., \& Barrett, A. M. (2008). Asymmetrical Visual-Spatial Attention in College Students Diagnosed with ADD/ADHD. Cognitive and Behavioral Neurology, 21, 176-178. http://dx.doi.org/10.1097/WNN.0b013e318185e6a9

Kent, K. M., Pelham Jr., W. E., Molina, B. S., Sibley, M. H., Waschbusch, D. A., Yu, J. et al. (2011). The Academic Experience of Male High School Students with ADHD. Journal of Abnormal Child Psychology, 39, 451-462.

http://dx.doi.org/10.1007/s10802-010-9472-4

Kessler, R. C., Adler, L., Ames, M., Barkley, R. A., Birnbaum, H., Greenberg, P. et al. (2005). The Prevalence and Effects of Adult Attention Deficit/Hyperactivity Disorder on Work Performance in a Nationally Representative Sample of Workers. Journal of Occupational and Environmental Medicine, 47, 565-572.

http://dx.doi.org/10.1097/01.jom.0000166863.33541.39

Kutcher, S., Aman, M., Brooks, S. J., Buitelaar, J., van Daalen, E., Fegert, J. et al. (2004). International Consensus Statement on Attention-Deficit/Hyperactivity Disorder (ADHD) and Disruptive Behaviour Disorders (DBDs): Clinical Implications and Treatment Practice Suggestions. European Neuropsychopharmacology, 14, 11-28.

http://dx.doi.org/10.1016/S0924-977X(03)00045-2 
Lara, C., Fayyad, J., de Graaf, R., Kessler, R. C., Aguilar-Gaxiola, S., Angermeyer, M. et al. (2009). Childhood Predictors of Adult Attention-Deficit/Hyperactivity Disorder: Results from the World Health Organization World Mental Health Survey Initiative. Biological Psychiatry, 65, 46-54. http://dx.doi.org/10.1016/j.biopsych.2008.10.005

Lauth, G. W., Heubeck, B. G., \& Mackowiak, K. (2006). Observation of Children with Attention-Deficit Hyperactivity (ADHD) Problems in Three Natural Classroom Contexts. British Journal of Educational Psychology, 76, 385-404. http://dx.doi.org/10.1348/000709905X43797

Lineweaver, T. T., Kercood, S., O’Keeffe, N. B., O’Brien, K. M., Massey, E. J., Campbell, S. J. et al. (2012). The Effects of Distraction and a Brief Intervention on Auditory and Visual-Spatial Working Memory in College Students with Attention Deficit Hyperactivity Disorder. Journal of Clinical and Experimental Neuropsychology, 34, 791-805. http://dx.doi.org/10.1080/13803395.2012.683854

Loe, I. M., \& Feldman, H. M. (2007). Academic and Educational Outcomes of Children with ADHD. Journal of Pediatric Psychology, 32, 643-654. http://dx.doi.org/10.1093/jpepsy/jsl054

Martin, A. J. (2014). Academic Buoyancy and Academic Outcomes: Towards a Further Understanding of Students with Attention-Deficit/Hyperactivity Disorder (ADHD), Students without ADHD, and Academic Buoyancy Itself. British Journal of Educational Psychology, 84, 86-107. http://dx.doi.org/10.1111/bjep.12007

Matza, L. S., Rentz, A. M., Secnik, K., Swensen, A. R., Revicki, D. A., Michelson, D. et al. (2004). The Link between Health-Related Quality of Life and Clinical Symptoms among Children with Attention-Deficit Hyperactivity Disorder. Journal of Developmental Behavioral Pediatrics, 25, 166-174. http://dx.doi.org/10.1097/00004703-200406000-00005

Meaux, J. B., Green, A., \& Broussard, L. (2009). ADHD in the College Student: A Block in the Road. Journal of Psychiatric and Mental Health Nursing, 16, 248-256. http://dx.doi.org/10.1111/j.1365-2850.2008.01349.x

Miranda, A., Jarque, S., \& Rosel, J. (2006). Treatment of Children with ADHD: Psychopedagogical Program at School versus Psychostimulant Medication. Psicothema, 18, 335-341.

Moher, D., Liberati, A., Tetzlaff, J., \& Altman, D. G. (2009). Preferred Reporting Items for Systematic Reviews and Meta-Analyses: The PRISMA Statement. British Medical Journal, 339, Article ID: b2535.

http://dx.doi.org/10.1136/bmj.b2535

National Institute of Health and Clinical Excellence (NICE) (2008). Guideline Diagnosis and Management of ADHD in Children, Young People and Adults.

Nijmeijer, J. S., Minderaa, R. B., Buitelaar, J. K., Mulligan, A., Hartman, C. A., \& Hoekstra, P. J. (2008). Attention-Deficit/Hyperactivity Disorder and Social Dysfunctioning. Clinical Psychology Review, 28, 692-708. http://dx.doi.org/10.1016/j.cpr.2007.10.003

Nolan, E. E., Gadow, K. D., \& Sprafkin, J. (2001). Teacher Reports of DSM-IV ADHD, ODD, and CD Symptoms in Schoolchildren. Journal of the American Academy of Child and Adolescent Psychiatry, 40, 241-249. http://dx.doi.org/10.1097/00004583-200102000-00020

Norvilitis, J. M., Sun, L., \& Zhang, J. (2010). ADHD Symptomatology and Adjustment to College in China and the United States. Journal of Learning Disabilities, 43, 86-94. http://dx.doi.org/10.1177/0022219409345012

Parker, D. R., Hoffman, S. F., Sawilowsky, S., \& Rolands, L. (2013). Self-Control in Postsecondary Settings: Students’ Perceptions of ADHD College Coaching. Journal of Attention Disorders, 17, 215-232. http://dx.doi.org/10.1177/1087054711427561

Polanczyk, G., de Lima, M. S., Horta, B. L., Biederman, J., \& Rohde, L. A. (2007). The Worldwide Prevalence of ADHD: A Systematic Review and Metaregression Analysis. The British Journal of Psychiatry, 164, 942-948. http://dx.doi.org/10.1176/ajp.2007.164.6.942

Prevatt, F., Proctor, B., Baker, L., Garrett, L., \& Yelland, S. (2011). Time Estimation Abilities of College Students with ADHD. Journal of Attention Disorders, 15, 531-538. http://dx.doi.org/10.1177/1087054710370673

Prevatt, F., Proctor, B., Best, L., Baker, L., Van, W. J., \& Taylor, N. W. (2012). The Positive Illusory Bias: Does It Explain Self-Evaluations in College Students with ADHD? Journal of Attention Disorders, 16, 235-243. http://dx.doi.org/10.1177/1087054710392538

Prins, P. J., Dovis, S., Ponsioen, A., ten Brink, E., \& van der Oord, S. (2011). Does Computerized Working Memory Training with Game Elements enhance Motivation and Training Efficacy in Children with ADHD? Cyberpsychology, Behavior, and Social Networking, 14, 115-122. http://dx.doi.org/10.1089/cyber.2009.0206

Rabiner, D. L., Anastopoulos, A. D., Costello, J., Hoyle, R. H., \& Swartzwelder, H. S. (2008). Adjustment to College in Students with ADHD. Journal of Attention Disorders, 11, 689-699. http://dx.doi.org/10.1177/1087054707305106

Rommelse, N. N., Altink, M. E., Fliers, E. A., Martin, N. C., Buschgens, C. J., Hartman, C. A. et al. (2009). Comorbid Problems in ADHD: Degree of Association, Shared Endophenotypes, and Formation of Distinct Subtypes. Implications for a Future DSM. Journal of Abnormal Child Psychology, 37, 793-804. http://dx.doi.org/10.1007/s10802-009-9312-6 
Scottish Intercollegiate Guidelines Network (SIGN) (2009). Attention Deficit and Hyperkinetic Disorders in Children and Young People. A National Clinical Guideline.

Semrud-Clikeman, M., \& Harder, L. (2011). Neuropsychological Correlates of Written Expression in College Students with ADHD. Journal of Attention Disorders, 15, 215-223. http://dx.doi.org/10.1177/1087054709359169

Shalev, L., Tsal, Y., \& Mevorach, C. (2007). Computerized Progressive Attentional Training (CPAT) Program: Effective Direct Intervention for Children with ADHD. Child Neuropsychology, 13, 382-388.

http://dx.doi.org/10.1080/09297040600770787

Shaw-Zirt, B., Popali-Lehane, L., Chaplin, W., \& Bergman, A. (2005). Adjustment, Social Skills, and Self-Esteem in College Students with Symptoms of ADHD. Journal of Attention Disorders, 8, 109-120. http://dx.doi.org/10.1177/1087054705277775

Shmulsky, S., \& Gobbo, K. (2007). Explanatory Style and College Students with ADHD and LD. Journal of Attention Disorders, 10, 299-305. http://dx.doi.org/10.1177/1087054706292103

Skounti, M., Philalithis, A., \& Galanakis, E. (2007). Variations in Prevalence of Attention Deficit Hyperactivity Disorder Worldwide. European Journal of Pediatrics, 166, 117-123. http://dx.doi.org/10.1007/s00431-006-0299-5

Sparks, R. L., Javorsky, J., \& Philips, L. (2004). College Students Classified with ADHD and the Foreign Language Requirement. Journal of Learning Disabilities, 37, 169-178. http://dx.doi.org/10.1177/00222194040370020701

Trampush, J. W., Miller, C. J., Newcorn, J. H., \& Halperin, J. M. (2009). The Impact of Childhood ADHD on Dropping out of High School in Urban Adolescents/Young Adults. Journal of Attention Disorders, 13, 127-136. http://dx.doi.org/10.1177/1087054708323040

Trimbos-instituut in opdracht van Landelijke Stuurgroep Multidisciplinaire Richtlijnontwikkeling in de GGZ (2005). Multidisciplinaire richtlijn ADHD Richtlijn voor de diagnostiek en behandeling van ADHD bij kinderen en jeugdigen.

Van der Kolk, A., Bouwmans, C. A., Schawo, S. J., Buitelaar, J. K., van Agthoven, M., \& Hakkaart-van Roijen, L. (2014). Association between Quality of Life and Treatment Response in Children with Attention Deficit Hyperactivity Disorder and Their Parents. The Journal of Mental Health Policy and Economics, 17, 119-129.

Verbeek, J., Ruotsalainen, J., \& Hoving, J. L. (2012). Synthesizing Study Results in a Systematic Review. Scandinavian Journal of Work, Environment Health, 38, 282-290. http://dx.doi.org/10.5271/sjweh.3201

Weiss, M. D., Gadow, K., \& Wasdell, M. B. (2006). Effectiveness Outcomes in Attention-Deficit/Hyperactivity Disorder. Journal of Clinical Psychiatry, 67, 38-45.

Wilmshurst, L., Peele, M., \& Wilmshurst, L. (2011). Resilience and Well-Being in College Students with and without a Diagnosis of ADHD. Journal of Attention Disorders, 15, 11-17. http://dx.doi.org/10.1177/1087054709347261

Wu, S. Y., \& Gau, S. S. (2013). Correlates for Academic Performance and School Functioning among Youths with and without Persistent Attention-Deficit/Hyperactivity Disorder. Research in Developmental Disabilities, 34, 505-515. http://dx.doi.org/10.1016/j.ridd.2012.09.004 
Scientific Research Publishing (SCIRP) is one of the largest Open Access journal publishers. It is currently publishing more than 200 open access, online, peer-reviewed journals covering a wide range of academic disciplines. SCIRP serves the worldwide academic communities and contributes to the progress and application of science with its publication.

Other selected journals from SCIRP are listed as below. Submit your manuscript to us via either submit@scirp.org or Online Submission Portal.
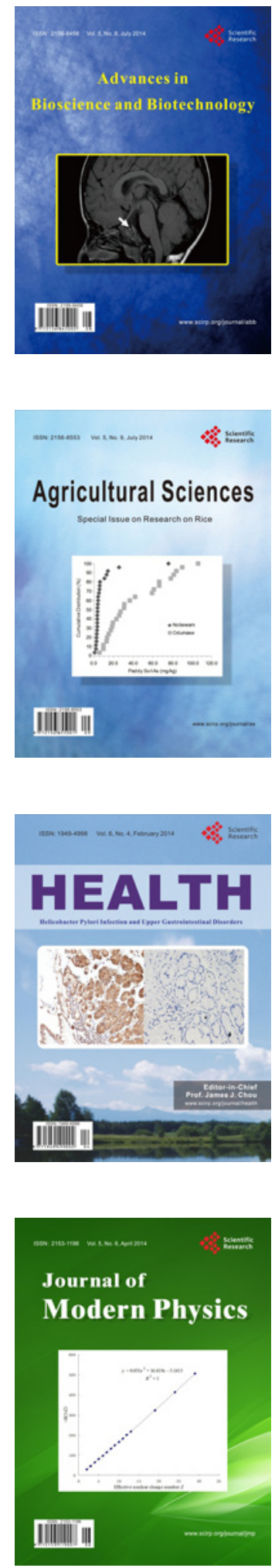
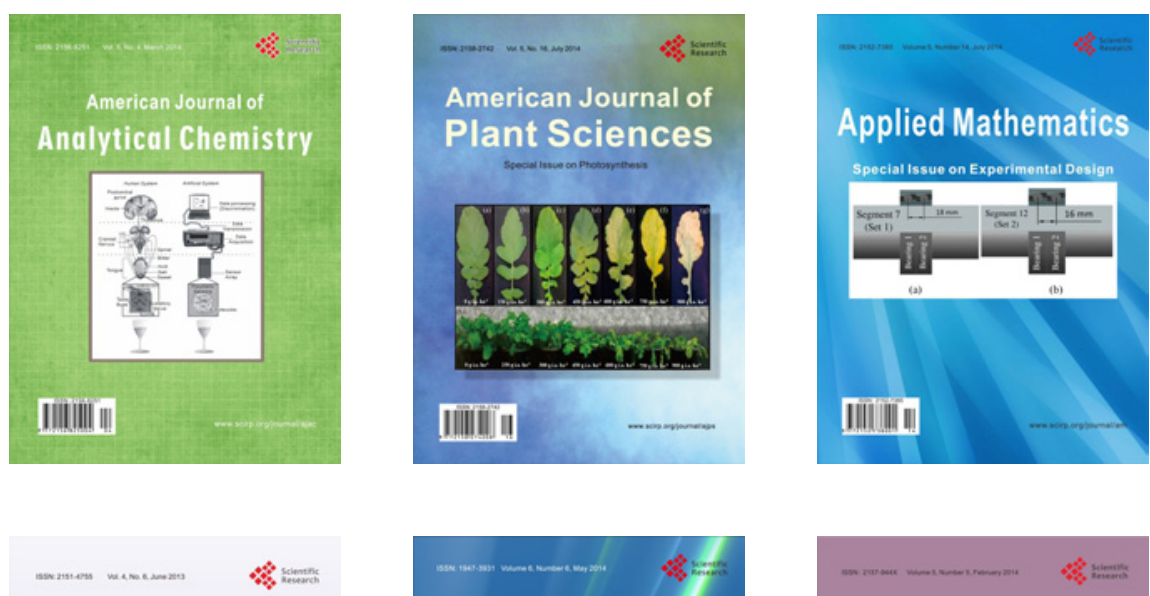

Creative Education
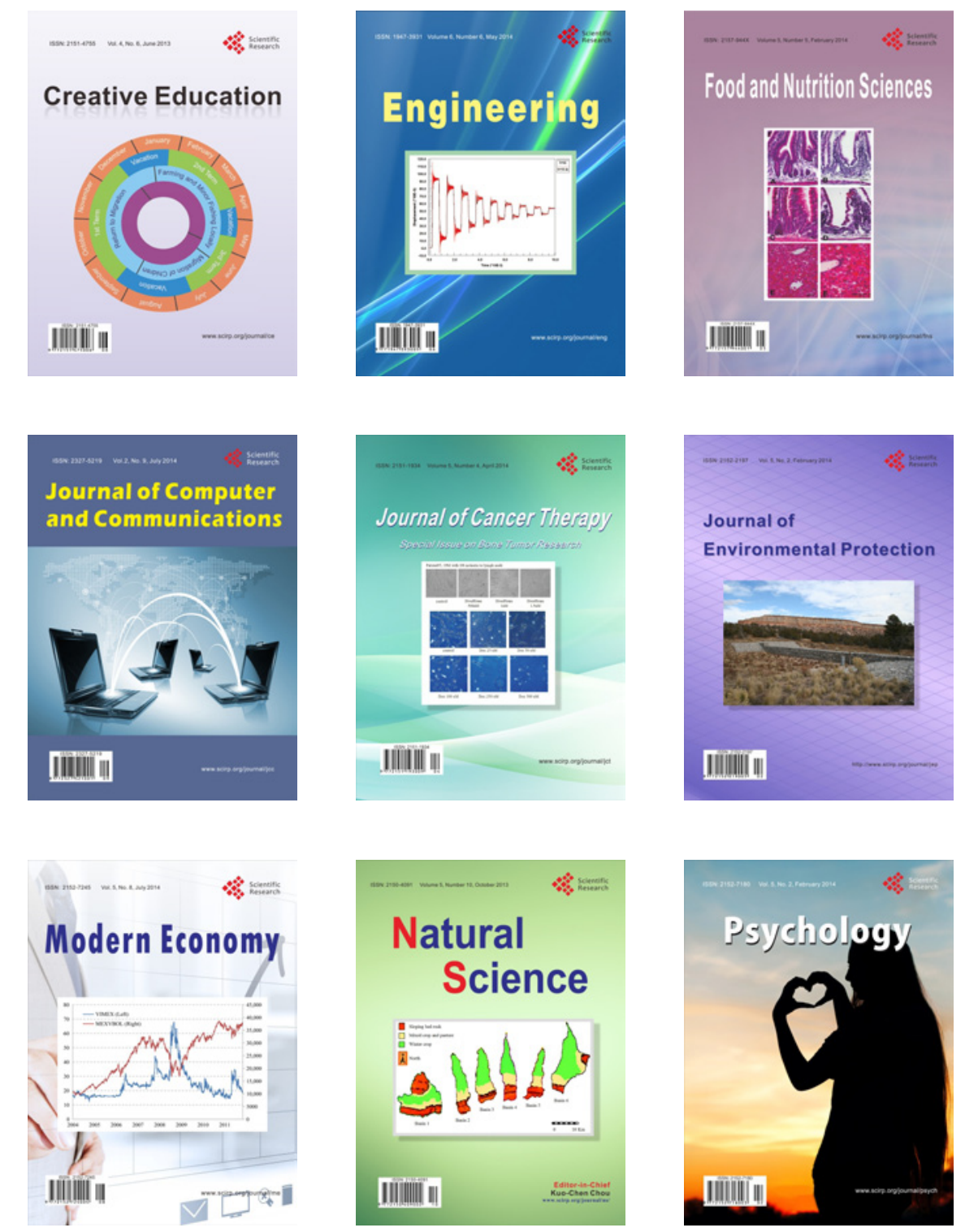